\title{
A simple approach to identify functional antibody variable genes in murine hybridoma cells that coexpress aberrant kappa light transcripts by restriction enzyme digestion
}

\author{
Romchat Kraivong, ${ }^{1}$ Prasit Luangaram, ${ }^{1}$ Narodom Phaenthaisong, ${ }^{1}$ Prida Malasit,${ }^{1,2}$ Watchara Kasinrerk, ${ }^{3,4}$ Chunya Puttikhunt ${ }^{1,2}$
}

\begin{abstract}
Background: Specific binding to target protein epitopes by a mouse monoclonal antibody (mAb) relies on its variable domains. However, the isolation of functional variable gene transcripts is sometimes hindered by co-expression of aberrant transcripts in hybridoma cells.
\end{abstract}

Objective: To develop general strategies for identifying the functional variable transcripts of both heavy $\left(\mathrm{V}_{\mathrm{H}}\right)$ and kappa light $\left(\mathrm{V}_{\mathrm{K}}\right)$ chains from mouse hybridomas.

Methods: $\mathrm{V}_{\mathrm{H}}$ and $\mathrm{V}_{\mathrm{\kappa}}$ genes of anti-dengue hybridoma clones were PCR-amplified using set of degenerate primers covering all mouse immunoglobulin families. $\mathrm{V}_{\mathrm{\kappa}}$ amplicons were additionally digested with BciVI to eliminate aberrant $\mathrm{V}_{\kappa}$ transcripts. The productive $\mathrm{V}_{\mathrm{H}}$ and $\mathrm{V}_{\kappa}$ sequences were identified by Immunogenetics (IMGT) database analysis and cloned into a dual human IgG expression vector to generate chimeric antibodies (chAbs) in mammalian cells. The reactivity of chAbs was tested by immunoblot and immunofluorescent assays.

Results: Among 17 tested hybridoma clones, $400 \mathrm{bp} \mathrm{V}_{\mathrm{\kappa}}$ amplicons were obtained using eight different $\mathrm{V}_{\mathrm{\kappa}}$ primers. Amplicons from productive $\mathrm{V}_{\kappa}$ transcripts are resistant to BciVI digestion, whereas BciVI-digested amplicons indicated aberrant $\mathrm{V}_{\kappa}$ transcripts. 500-bp productive $\mathrm{V}_{\mathrm{H}}$ amplicons could be obtained from all clones using a set of five $\mathrm{V}_{\mathrm{H}}$ primers. The productive $\mathrm{V}_{\mathrm{H}} / \mathrm{V}_{\mathrm{K}}$ genes of three anti-dengue NS1 mAbs (m2G6, m1F11 and m1A4) were cloned and mouse-human chAbs were generated. The binding reactivities of the chAbs to dengue NS1 were similar to the original mAbs.

Conclusions: A general protocol to identify productive/functional $\mathrm{V}_{\mathrm{H}}$ and $\mathrm{V}_{\mathrm{\kappa}}$ genes was demonstrated. The method is useful for producing chAbs and genetic archiving of valuable hybridoma cell lines.

Key words: Aberrant variable transcripts, chimeric antibody, dengue virus, functional variable transcripts, mouse hybridoma cells

\footnotetext{
Affiliations:

Medical Biotechnology Research Unit, National Center for Genetic Engineering and Biotechnology (BIOTEC), National Science and Technology Development Agency (NSTDA), Bangkok, Thailand

Division of Dengue Hemorrhagic Fever Research, Department of Research and Development, Faculty of Medicine Siriraj Hospital, Mahidol University, Bangkok, Thailand

Biomedical Technology Research Center, National Center for Genetic Engineering and Biotechnology (BIOTEC), National Science and Technology Development Agency (NSTDA), Chiang Mai, Thailand

${ }^{4}$ Division of Clinical Immunology, Department of Medical

Technology, Faculty of Associated Medical Sciences,

Chiang Mai University, Chiang Mai, Thailand
}

Romchat Kraivong and Prasit Luangaram contributed equally to this work

\section{Corresponding author:}

Chunya Puttikhunt

Medical Biotechnology Research Unit,

National Center for Genetic Engineering and Biotechnology,

$12^{\text {th }}$ Floor Adulyadejvikrom Bldg., Siriraj Hospital,

Bangkok 10700, Thailand

E-mail: chunyapk@biotec.or.th

\section{Introduction}

Hybridoma technology is used to produce monoclonal antibodies (mAbs) by fusion of murine B cells and myeloma cells. However, some hybridoma clones may lose the ability to produce $\mathrm{mAb}$ due to genetic instability and/or inappropriate culturing and storage conditions. Thus, archiving of variable genes should be performed for safekeeping of valuable clones. 
In addition, mouse variable genes can be fused to the constant region of an immunoglobulin gene derived from another species in order to generate chimeric antibodies (chAbs), which are useful for various applications. For example, chAbs are used therapeutically in humans, in which the variable genes are fused to the human immunoglobulin backbone to minimize irrelevant immunogenicity. To date, a number of chAbs have been used for treatment of disease, e.g. Rituxan (rituximab) for rheumatoid arthritis and Remicade (Infliximab) for auto-immune diseases. ${ }^{1,2}$

For the generation of chAbs, it is necessary to clone genes encoding $\mathrm{V}_{\mathrm{H}}$ and $\mathrm{V}_{\mathrm{\kappa}}$ of target mAbs from mouse hybridoma cell lines. However, aberrant immunoglobulin mRNAs are found in hybridoma cells derived from MOPC21 myeloma fusion partners, which interfere with the cloning of the desired variable gene transcripts. Aberrant $\mathrm{V}_{\kappa}$ sequences frequently contain a premature stop codon at a position 105 and the codon replacement of cysteine to tyrosine at position $23 .{ }^{3}$

Several strategies have been applied to eliminate aberrant $\mathrm{V}_{\mathrm{K}}$ transcripts, such as peptide sequencing and antisense directed $\mathrm{RNase} H$ to digest the aberrant $\mathrm{V}_{\kappa}$ mRNA, but these strategies are ineffective. ${ }^{4}$ However, most aberrant $V_{\kappa}$ sequences contain recognition sites for some restriction endonucleases. ${ }^{5}$ A BciVI site, for example, is commonly located in aberrant transcript sequences (96\%). Therefore, BciVI-sensitive aberrant $\mathrm{V}_{\kappa}$ can be distinguished from the BciVI-resistant sequences that encode functional $V_{k}$. However, since the $a b-$ errant $\mathrm{V}_{\mathrm{K}}$ transcripts in most myeloma partners are abundant and preferentially amplified, a rare functional $\mathrm{V}_{\mathrm{\kappa}}$ genes are then hardly to be recovered after $B c i$ VI digestion, which still allowed low efficiency in downstream cloning step. ${ }^{6}$

We have generated several mouse hybridoma clones producing mAbs against dengue virus proteins, which are useful for immunopathology of dengue diseases, diagnostics and dengue vaccine development. We wished to clone $\mathrm{V}_{\mathrm{H}}$ and $\mathrm{V}_{\mathrm{L}}$ genes from these valuable hybridoma clones as genetic archive in case the cells lose viability. Moreover, the cloned immunoglobulin genes are required to generate chAbs. The presence of aberrant $\mathrm{V}_{\mathrm{K}}$ transcripts in these clones could prevent the isolation of the desired functional genes. In this study, we proposed a strategy to select functional variable transcripts from murine hybridoma clones by using two sets of specific primers covering most of the mouse immunoglobulin genes to selectively amplify different $\mathrm{V}_{\mathrm{H}}$ or $\mathrm{V}_{\mathrm{K}}$ gene sequences. PCR products from aberrant $V_{\kappa}$ transcripts can be identified by $B c i$ VI digestion. Functional transcript sequences of variable domains could be selectively amplified from 17 hybridoma cell lines producing antibodies against dengue virus proteins (NS1, nonstructural protein 1; E, envelope; and prM, pre-membrane). Functional $\mathrm{V}_{\mathrm{H}}$ and $\mathrm{V}_{\mathrm{\kappa}}$ genes of three hybridoma cell lines with the human IgG1 constant region were assembled to generate chAbs. The functional properties of the chAbs were compared with the corresponding original mAbs.

\section{Methods \\ Hybridoma cells and viruses}

Seventeen mouse hybridoma cell lines producing mAbs against dengue prM, E and NS1 proteins were used in this study. Most of them were generated from X63-Ag8.653 myeloma fusion partner, except $4 \mathrm{G} 2$ and $2 \mathrm{H} 2$ which were from $\mathrm{X}-63-\mathrm{Ag} 8 .^{7-10} \mathrm{C} 6 / 36$ or BHK cells were infected with prototypic strains of four dengue viruses, DENV1 (Hawaii), DENV2 (16681), DENV3 (H87), and DENV4 (H241) and used for expression of antigens in immunoassays.

\section{RNA isolation and cDNA synthesis}

Total RNA was isolated from hybridomas with the RNeasy mini kit (Qiagen, Germany) and cDNA was synthesized with oligo $(\mathrm{dT})_{20}$ using Superscript III reverse transcriptase (Life Technologies, USA) according to the manufacturers' protocols.

\section{PCR amplification of $V_{H}$ and $V_{\mathrm{K}}$ genes}

$\mathrm{V}_{\mathrm{H}}$ and $\mathrm{V}_{\kappa}$ transcripts were amplified from hybridoma cDNAs using Phusion high fidelity DNA polymerase (NEB, USA). Eight sense degenerate primers binding to leader sequences of $\mathrm{V}_{\mathrm{K}}$ regions and an antisense primer binding to the constant kappa light chain region were designed. PCRs were carried out for 50 cycles with $10 \mathrm{~s}$ denaturing $\left(98^{\circ} \mathrm{C}\right), 10 \mathrm{~s}$ annealing $\left(55^{\circ} \mathrm{C}\right), 30 \mathrm{~s}$ extension $\left(72^{\circ} \mathrm{C}\right)$ and a final extension of $5 \mathrm{~min}\left(72^{\circ} \mathrm{C}\right)$. The size of $\mathrm{V}_{\mathrm{K}}$ PCR product was about 400 base pairs (bp). For $\mathrm{V}_{\mathrm{H}}$ amplification, five sense primers located upstream of the $\mathrm{V}_{\mathrm{H}}$ regions or the highly conserved sequences at the beginning of the FR1 region and six antisense primers located in the constant regions of IgG1, IgG2a and IgM were used. To enhance yield of $\mathrm{V}_{\mathrm{H}}$ product, a primary PCR was performed with the $\mathrm{V}_{\mathrm{H}}$ sense and outer antisense primers for 35 cycles with $10 \mathrm{~s}$ denaturing $\left(98^{\circ} \mathrm{C}\right), 10 \mathrm{~s}$ annealing $\left(55^{\circ} \mathrm{C}\right), 40 \mathrm{~s}$ extension $\left(72^{\circ} \mathrm{C}\right)$ and a final extension of $5 \mathrm{~min}$ $\left(72^{\circ} \mathrm{C}\right)$. The primary PCR product was re-amplified with the same PCR protocol in a semi-nested PCR using inner antisense primers and the same sense primer. The size of the $V_{H}$ semi-nested PCR product was about $500 \mathrm{bp}$.

\section{Identification of aberrant variable gene transcripts and gene cloning}

The $\mathrm{V}_{\mathrm{K}}$ PCR products were subsequently digested with BciVI (NEB) restriction enzyme. The 400 bp BciVI-resistant $\mathrm{V}_{\mathrm{K}}$ as well as the $500 \mathrm{bp} \mathrm{V}_{\mathrm{H}}$ PCR products were cloned into the pGEM-T TA cloning vector (Promega). Plasmids containing $\mathrm{V}_{\mathrm{H}}$ or $\mathrm{V}_{\mathrm{K}}$ gene were purified from transformed $E$. coli strain DH5a bacteria and verified by DNA sequencing. Plasmids with cloned $\mathrm{V}_{\mathrm{H}}$ or $\mathrm{V}_{\kappa}$ sequences were analyzed with BLAST and the IMGT V-QUEST database tool (http://www. imgt.org/IMGT_vquest/vquest). ${ }^{11}$ 


\section{Construction of dual antibody expression plasmid}

The dual expression plasmid containing HER2/neu receptor specific humanized IgG1/ $\kappa$ antibody isotype (pVITRO1-hTrastuzumab-IgG1k), a gift from Andrew Beavil (Addgene plasmid \# 61883), was used. Variable domains of the HER2/neu receptor in the dual plasmid were replaced with $\mathrm{V}_{\mathrm{H}}$ and $\mathrm{V}_{\mathrm{K}}$ genes derived from mAbs using the polymerase incomplete primer extension (PIPE) technique. ${ }^{12}$ Briefly, pVITRO1-hTrastuzumab-IgGl $\kappa$ was amplified to obtain two linearized plasmid fragments by PCR using two vector-specific primer pairs (Linear_Kfwd/Linear_Hrev and Linear_Hfwd/ Linear_Krev; $V_{H}$ and $V_{k}$ genes cloned in pGEM-T plasmid vector were amplified with specific primer pairs for each $\mathrm{mAb}$ (e.g., 2G6VH-fwd/rev and 2G6VK-fwd/rev). Four PCR fragments with overlapping ends were mixed and annealed to make circular plasmids at $50^{\circ} \mathrm{C}$ for 1 hour, and then treated with the restriction enzyme $D p n \mathrm{I}$ (NEB). The assembled PCR products were transformed into E. coli strain DH5a. The pVITRO1 plasmids containing the cloned $V_{H}$ and $V_{k}$ genes for production of antibodies against dengue proteins were validated by nucleotide sequencing (Macrogen).

\section{Transfection and recombinant antibody production}

Two $\mu \mathrm{g}$ of a plasmid encoding $\mathrm{V}_{\mathrm{H}}$ and $\mathrm{V}_{\mathrm{k}}$ transcripts was transfected into human embryonic kidney cell line 293T (ATCC, USA) with Lipofectamine 2000 (Thermo Fisher, USA). Supernatants containing chAbs were harvested to assay for expression.

\section{Characterization of chAbs}

The obtaining chAbs were characterized for the presence of human immunoglobulin and their specific reactivity to dengue NS1. The human immunoglobulin of chAbs were tested by dot blot analysis using HRP-conjugated goat anti-human immunoglobulins (Jackson Immuno Research, USA), specific to human immunoglobulin. To determine specific binding reactivity in comparison with mAbs, DENV1 to 4 -infected cell lysates or supernatants were tested with chAbs by dot blot assay and Western blot analysis. For secondary or conjugated antibody, HRP-conjugated goat anti-human immunoglobulins was used followed by chAbs, whereas, HRP-conjugated anti-mouse Igs (Dako, USA) was followed by mAbs. Antibody reactivity on DENV1 to 4 -infected cells was also tested by immunofluorescent assay (IFA), in which anti-E $\mathrm{mAb}(\mathrm{m} 4 \mathrm{G} 2)$ was used to confirm dengue virus infection.

\section{Competitive binding ELISA}

The purified NS1 protein from DENV2 infected Vero cells (10 ng) was coated on ELISA wells. The blocking $\mathrm{mAb}$ was initially added to NS1-coated ELISA wells from 0.17 to 100 $\mu \mathrm{g} / \mathrm{ml}(100 \mu \mathrm{l})$ for 1 hour. PBS was used as negative control. The chAb was subsequently added to those ELISA wells to obtain a final concentration of $6 \mu \mathrm{g} / \mathrm{ml}$ for another 1 hour. The bound chAb-NS1 complex was detected with goat-anti-human IgG-HRP (dilution 1:1000; P214, Dako). The TMB substrate (Thermo Fisher Scientific, USA) was used to develop reaction colors and OD reading at $450 \mathrm{~nm}$ (A450) was measured by ELISA reader. The percentage of blocking (\% blocking) were calculated as followed:
$\%$ Blocking of $\mathrm{chAb}=(\mathrm{A} 450$ of control well $-\mathrm{A} 450$ of the test well) $\times 100 / \mathrm{A} 450$ of control well Where control well is A450 obtained from chAb without blocking antibody (no $\mathrm{mAb}$ ). Test well is A450 obtained from chAb reactivity in the presence of blocking $\mathrm{mAb}(+\mathrm{mAb})$.

\section{Results \\ Coexpression of functional and aberrant $V_{\kappa}$ transcripts in murine hybridoma cells}

Three hybridoma clones (2G6,1F11 and 1A4) producing mAbs against dengue NS1 proteins were selected for initial characterization of $V_{k}$ genes. $V_{k}$ PCR products of the expected size (400 bp) were obtained using a mixture of leader light chain primers and a constant kappa light chain primer. Analysis of cloned nucleotide sequences indicated that only the 2G6 clone $V_{\kappa}$ sequence could produce functional antibody protein. In contrast, $V_{k}$ sequences from clones $1 \mathrm{~F} 11$ and $1 \mathrm{~A} 4$ contained a stop codon at a position 105 and Tyr at position 23, the hallmarks of aberrant $\mathrm{V}_{k}$ genes. These aberrant $\mathrm{V}_{k}$ sequences were identical to those of several hybridoma clones derived from the X63-Ag8.653 myeloma cell line as previously reported. ${ }^{3,13}$ As a $B c i$ VI recognition site is commonly found in aberrant $V_{k}$ genes, we hypothesized that mouse hybridoma clones with functional or aberrant $V_{k}$ genes could be distinguished by digestion of $\mathrm{V}_{k}$ gene PCR products with $B c i \mathrm{VI}$. As expected from sequence analysis, the PCR product from clone $2 \mathrm{G} 6$ was resistant to BciVI treatment, but an additional digested 200 bp DNA fragment was observed from the 1F11 and $1 \mathrm{~A} 4$ clones producing aberrant $\mathrm{V}_{\mathrm{K}}$ (Figure 1B, lanes 1-3), indicating the presence of aberrant $V_{k}$ transcripts. Although $\mathrm{V}_{\mathrm{k}}$ gene PCR products of the expected size (400 bp) were obtained from all 17 clones (Figure 1A), BciVI-digested products (200 bp) were obtained from $\mathrm{V}_{\mathrm{k}}$ amplicons derived from most of the tested clones, except $2 \mathrm{H} 2$ and $1 \mathrm{~B} 10$ (Figure 1B). These results suggest that aberrant $V_{k}$ genes are present in the majority of our mouse hybridoma clones. However, the presence of $400 \mathrm{bp}$ bands resistant to $B c i \mathrm{VI}$ treatment in addition to digested $200 \mathrm{bp}$ bands for all clones (Figure 1B) suggested the coexpression of functional and aberrant $\mathrm{V}_{\mathrm{K}}$ transcripts, perhaps from different genes.

\section{Functional $V_{\kappa}$ genes from clones coexpressing aberrant $V_{k}$ genes}

From the coexpression of functional and aberrant $V_{k}$ transcripts, we hypothesized that the functional $V_{k}$ transcripts could be selectively PCR-amplified using different sense primers binding to variable regions. Each of eight different sense primers (LVk) with a constant kappa light chain anti-sense primer were initially tested for PCR amplification using cDNA from three clones (1F11, 1A4 and 2G6). The $400 \mathrm{bp} \mathrm{V}_{\mathrm{k}}$ PCR product was obtained by some, but not all individual primers from each clone (Figure 2A). Subsequent treatment with $B c i \mathrm{VI}$ was performed to distinguish functional $\mathrm{V}_{\mathrm{k}}$ genes PCR products (resistant to digestion) from aberrant $V_{k}$ genes (sensitive to digestion) (Figure 2B). The BciVI-resistant products from 2G6 (obtained using primer LVk20), and these from $1 \mathrm{~F} 11$ and 1A4 (obtained using primer LVk6) were cloned. 
a NS1

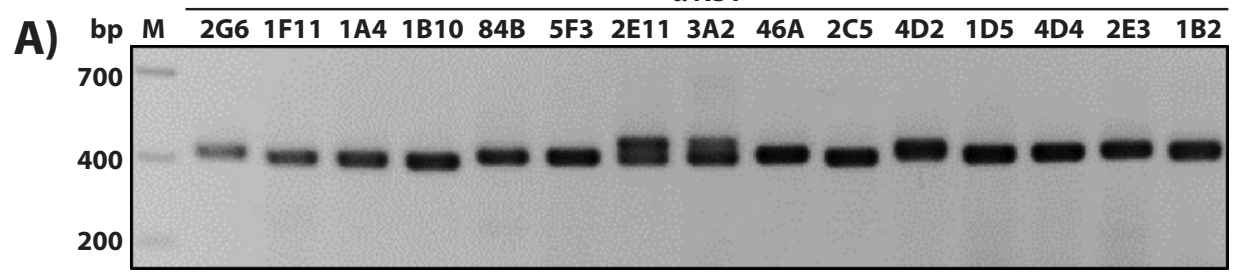

B)

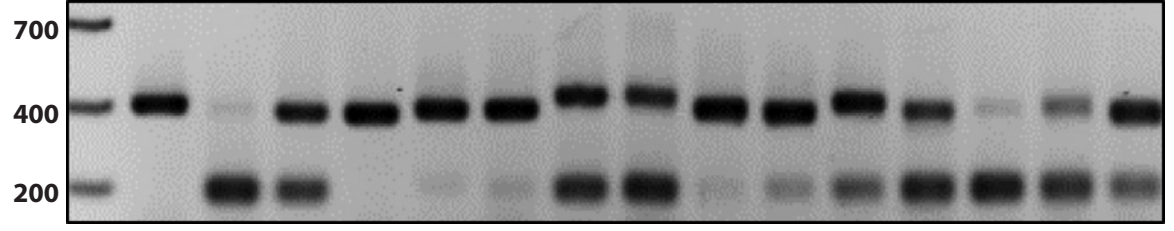

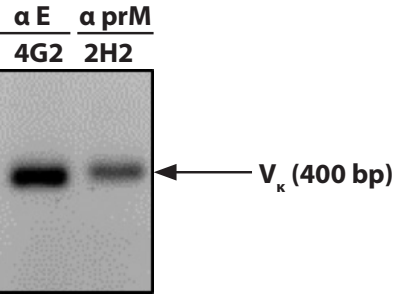

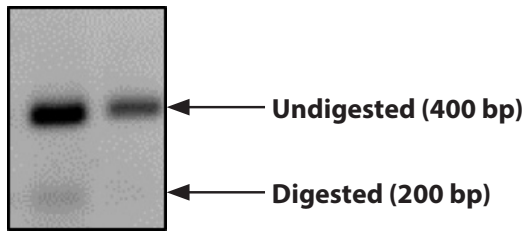

Figure 1. Identification of aberrant $\mathrm{V}_{\mathrm{k}}$ transcripts in hybridoma cells. The $\mathrm{V}_{\mathrm{k}}$ transcripts derived from first strand cDNAs were amplified using a mixture of eight sense primers binding to the leader light chain and the anti-sense constant kappa light chain primer. The $\mathrm{V}_{\mathrm{\kappa}}$ PCR products were (A) left untreated or (B) treated with BciVI prior to separation by agarose gel electrophoresis. ZipRuler express DNA ladder 2 (Thermo Fisher) was separated in the lane labeled M. Amplicons of the size expected for $\mathrm{V}_{\mathrm{K}}$ transcripts are marked as $\mathrm{V}_{\mathrm{\kappa}}(400 \mathrm{bp})$. Amplicon undigested with BciVI corresponds to putatively productive $\mathrm{V}_{\mathrm{k}}$ transcript (marked as Undigested (400 bp)), whereas BciVI digested amplicon corresponds to putatively aberrant $\mathrm{V}_{\mathrm{K}}$ transcript (marked as Digested $(200 \mathrm{bp})$ ). PCR products of anti-NS1 antibody clones were separated in lanes 2-15 (clone identifiers shown above the lanes), whereas PCR products of anti-E (4G2) and anti-prM (2H2) antibody clones were separated in lane 16 and 17 , respectively.

A)
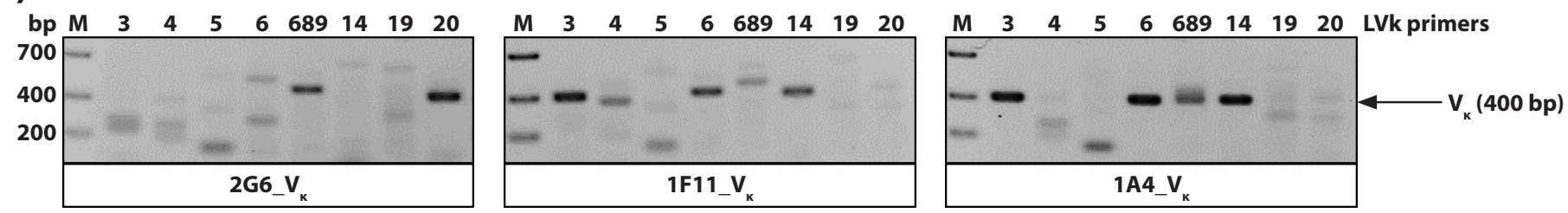

B)
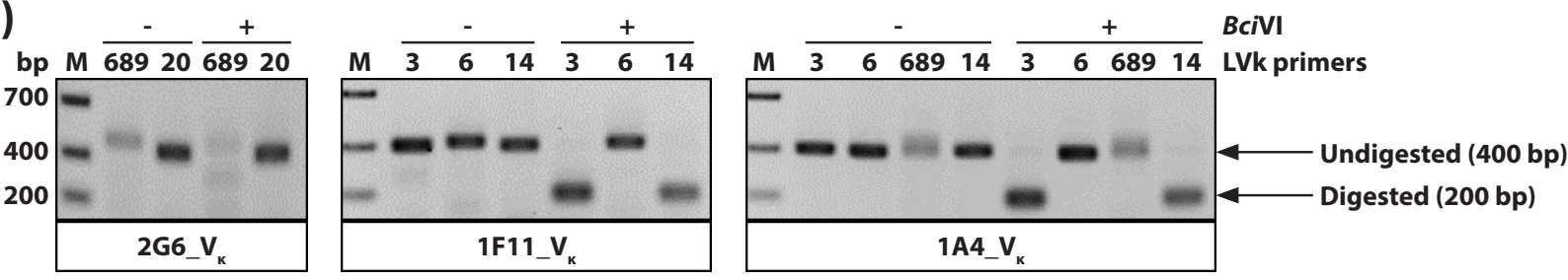

Figure 2. Identification of aberrant $\mathrm{V}_{\mathrm{\kappa}}$ transcripts by BciVI digestion. (A) PCR products derived from first strand cDNAs of hybridoma clones 2G6, 1F11 and 1A4 were generated with eight different sense primers (LVk primers) and separated by agarose gel electrophoresis. Amplicons of the size expected for $\mathrm{V}_{\mathrm{k}}$ transcripts are marked as $\mathrm{V}_{\mathrm{k}}(400 \mathrm{bp})$. (B) $\mathrm{V}_{\mathrm{k}}$ transcripts amplified with the indicated primers were either left untreated (-) or digested with BciVI (+) prior to agarose gel electrophoresis. Amplicon undigested with BciVI corresponds to putatively productive $\mathrm{V}_{\kappa}$ transcript (marked as Undigested (400 bp)), whereas BciVI digested amplicon corresponds to putatively aberrant $\mathrm{V}_{\mathrm{\kappa}}$ transcript (marked as Digested (200 bp)). Lane M indicates ZipRuler express DNA ladder 2 (Thermo Fisher) (bp).

Sequencing of the cloned $V_{\kappa}$ genes demonstrated that all cloned genes encoded functional $\mathrm{V}_{\kappa}$ as expected. The same experimental protocol was applied to the other hybridoma clones, and BciVI-resistant $\mathrm{V}_{\mathrm{\kappa}}$ amplicons were obtained using different sense primers. Sequencing of these BciVI-resistant $\mathrm{V}_{\mathrm{K}}$ gene products showed that all encoded functional $\mathrm{V}_{\mathrm{K}}$ gene sequences. A few exceptions were found in clones $4 \mathrm{G} 2$ and $2 \mathrm{H} 2$ in which these $\mathrm{V}_{\mathrm{K}}$ gene products amplified by primer LVk689, but not the others, were identified as endogenous $\mathrm{V}_{\mathrm{K}}$ genes from myeloma cells. These results suggested that the protocol for obtaining functional $\mathrm{V}_{\kappa}$ genes is reproducible among different mouse hybridoma clones.

\section{Amplification of $V_{H}$ transcripts}

PCR amplification of the $\mathrm{V}_{\mathrm{H}}$ gene was initially tested from three hybridoma clones (2G6, 1F11 and 1A4). $500 \mathrm{bp} \mathrm{V}_{\mathrm{H}}$ gene products were obtained by semi-nested PCR using different $\mathrm{V}_{\mathrm{H}}$ primer pairs (Figure 3). Sequencing analysis indicated that all cloned $\mathrm{V}_{\mathrm{H}}$ genes encoded functional antibody proteins. $\mathrm{V}_{\mathrm{H}}$ transcripts of the other 14 hybridoma clones were PCR amplified in the same manner and verified by sequencing analysis. Functional $\mathrm{V}_{\mathrm{H}}$ transcripts were obtained from all hybridoma clones, except $1 \mathrm{~B} 2$ of which the aberrant sequence was generated by a frameshift at the CDR3 region. The aberrant $\mathrm{V}_{\mathrm{H}}$ sequence from $1 \mathrm{~B} 2$ is not described in previous reports. ${ }^{6,14}$ 


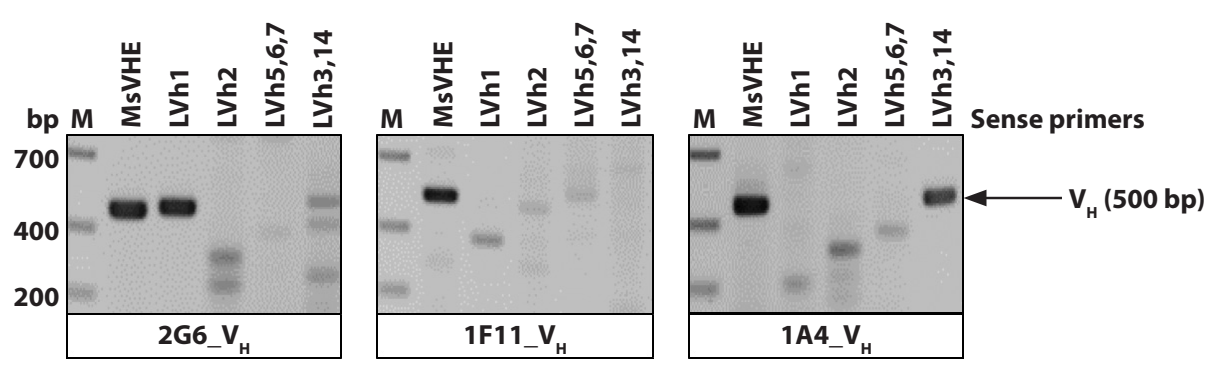

Figure 3. Amplification of $\mathrm{V}_{\mathrm{H}}$ transcripts in hybridoma cells. $\mathrm{V}_{\mathrm{H}}$ amplicons derived from first strand cDNAs of hybridoma clones 2G6, 1F11 and 1A4 were obtained by PCR with five different sense primers. The PCR products were separated by agarose gel electrophoresis. Amplicons of the size expected for $\mathrm{V}_{\mathrm{H}}$ transcripts are marked as $\mathrm{V}_{\mathrm{H}}(500 \mathrm{bp}$ ). Lane M indicates ZipRuler express DNA ladder 2 (Thermo Fisher) (bp). The reactions with different sense primers are indicated above the lanes.
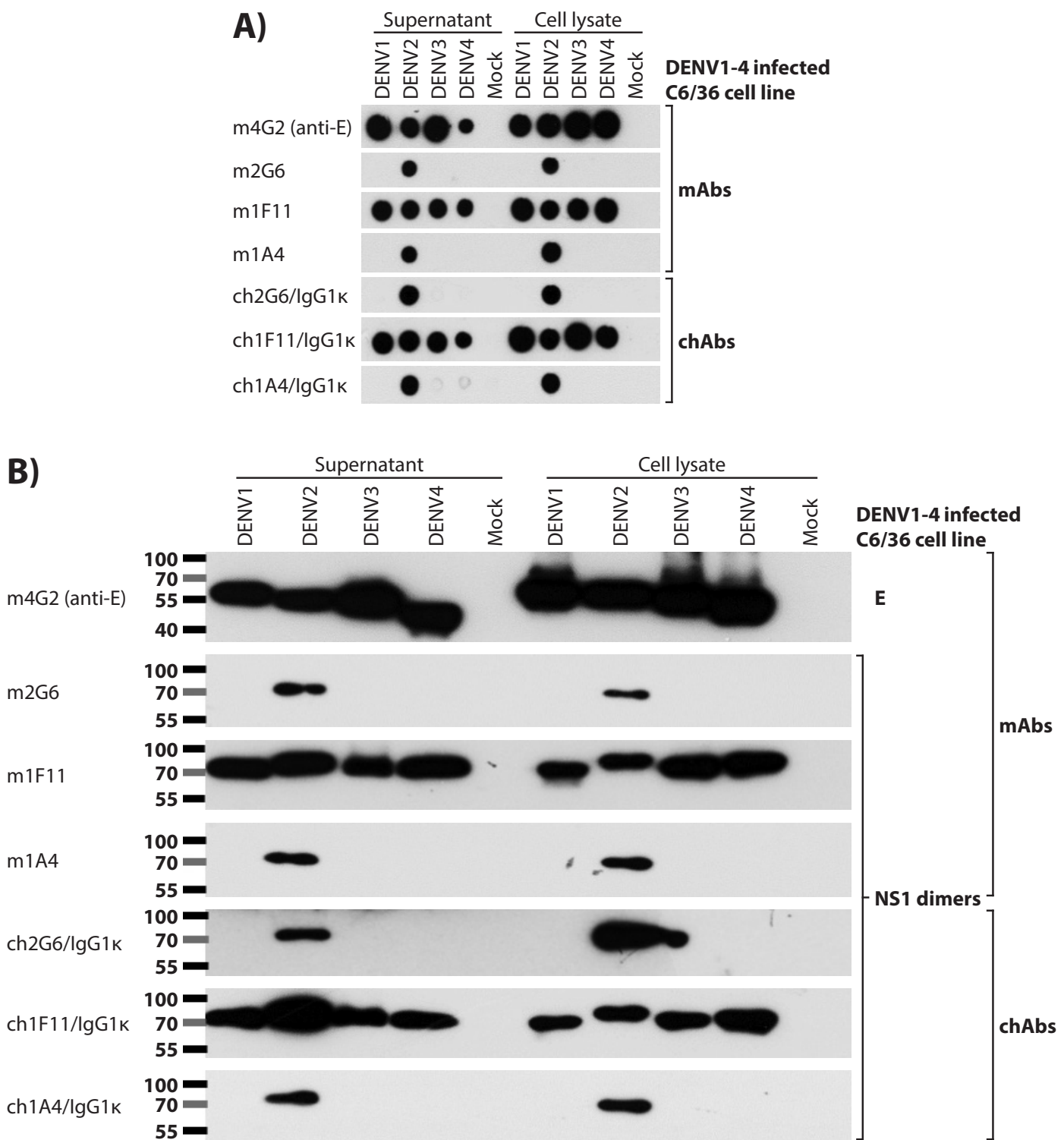

Figure 4. Functional testing of chimeric antibodies. C6/36 cells were infected with one of four serotypes of dengue virus (DENV1-4). Supernatants and cell lysates of infected and mock-infected cells were analyzed by (A) dot blot and (B) Western blot assays by probing with either murine antibodies (mAbs) or chimeric antibodies (chAbs) specific to the NS1 protein (2G6, 1F11 and 1A4). Anti-E (m4G2) was used as a positive control to detect the dengue virus E antigen in infected cells. The migrations of protein markers (PageRuler prestained protein ladder; Thermo Fisher) are indicated on the left of the blots in (B). 
Therefore, we deposited this novel aberrant $\mathrm{V}_{\mathrm{H}}$ sequence in the GenBank database (GenBank accession no. MF174854).

\section{Generation and functional testing of chAbs}

To verify the functionality of cloned $\mathrm{V}_{\mathrm{H}}$ and $\mathrm{V}_{\mathrm{K}}$ genes, chAbs containing mouse variable region and human IgG1 constant region were generated. The putatively functional $\mathrm{V}_{\mathrm{H}}$ and $\mathrm{V}_{\mathrm{\kappa}}$ genes obtained from mouse hybridoma clones 2G6, $1 \mathrm{~F} 11$ and $1 \mathrm{~A} 4$ were sub-cloned into the dual expression plasmid pVITRO/IgG1к. Recombinant plasmids were transfected to $293 \mathrm{~T}$ cells. Three transfected cell lines were established that secreted chAbs to dengue NS1 protein, designated as ch2G6/

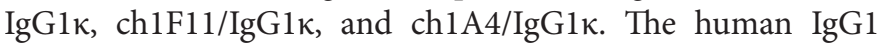
constant region of these chAbs cross-reacted with anti-human immunoglobulins (Igs)-HRP, but not with anti-mouse Igs-HRP, by dot blot assay. In addition, by competitive binding ELISA, we showed that NS1 binding of ch1F11 and ch1A4 Abs can be blocked by their original mAbs, but not by other clones. This result indicated the same recognition epitope on NS1 protein of original $\mathrm{mAb}$ and its corresponding chAb. Functional assays were performed to test the activity of chAbs against dengue NS1 proteins in comparison with the original mouse mAbs (m2G6, m1F11 and m1A4). By im-

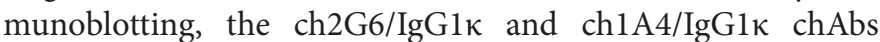
reacted with DENV2 NS1 proteins, similar to the corresponding m2G6 and m1A4 antibodies, whereas the ch1F11/ IgG1 $\kappa$ chAb recognized NS1 proteins of all four dengue serotypes, similar to the corresponding m1F11 (Figure 4). The three chAbs were tested for NS1 detection in dengue-infected fixed cells by IFA (Figure 5). Similar staining patterns to the original mouse hybridoma clones were found, in which the ch1F11 antibodies bound to NS1 proteins located in the cytoplasm of all dengue-infected cells, whereas ch1A4 antibodies recognized NS1 in DENV2-infected cells. Moreover, the ch2G6 antibodies strongly detected NS1 proteins in DENV2-infected cells, with weaker detection in DENV1-infected cells. None of the chAbs showed non-specific binding to mock-infected cells.
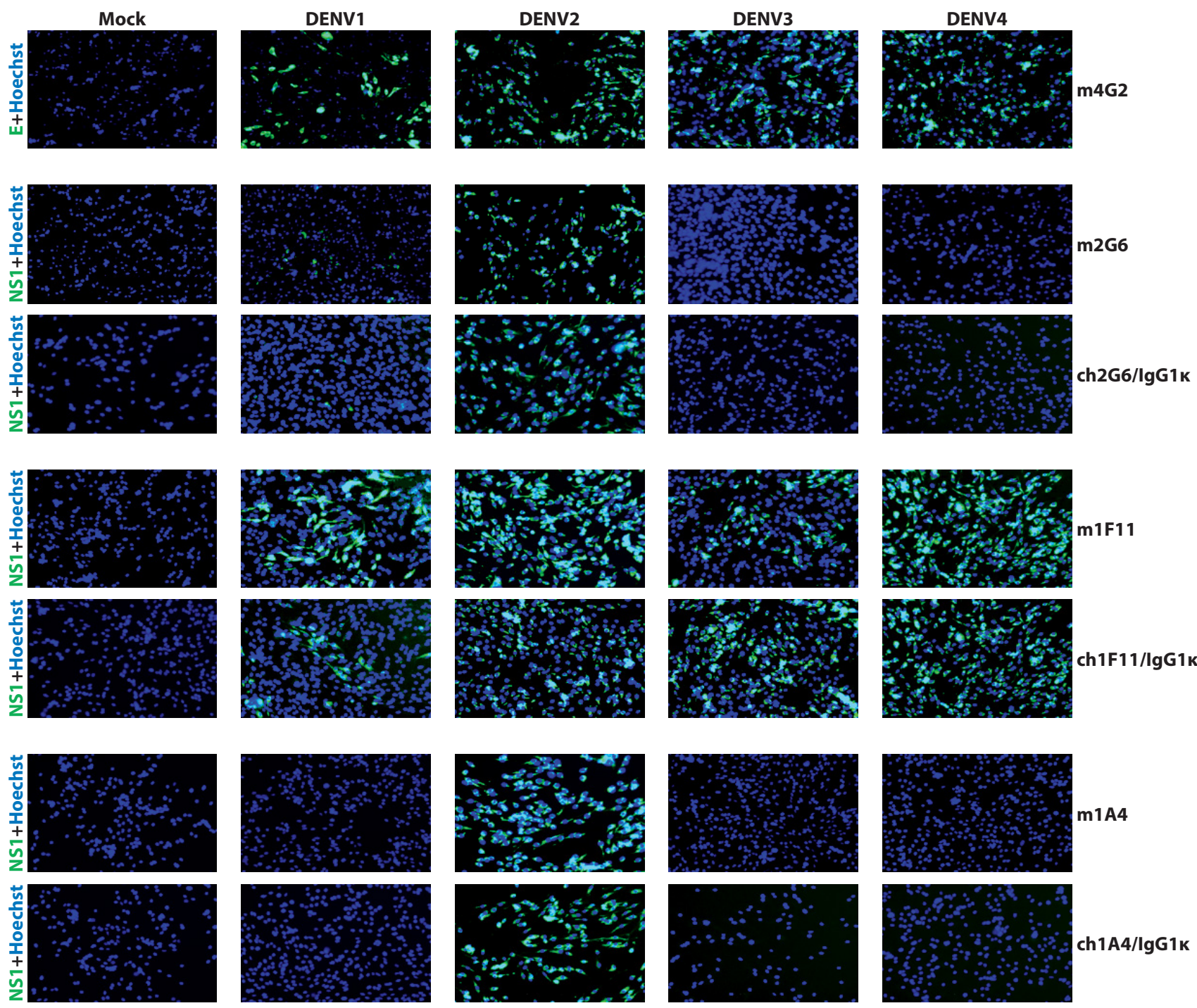

Figure 5. Immunofluorescent cell staining by recombinant antibodies. BHK cells were infected with one of four serotypes of dengue virus (DENV1-4). NS1 staining (green) was performed with either a mouse monoclonal antibody (mAb) (2G6, 1F11 or 1A4), followed with goat anti-mouse IgG-Alexa 488 or their chimeric counterpart (chAb/IgG1к), followed with goat anti-human IgG-Alexa 488. Infectivity was confirmed by staining the dengue virus E protein with m4G2 (green). Hoechst33342 dye (blue) was used to stain cell nuclei. Cell staining was observed under EVOS cell imaging systems, at magnification of 20 (20x). 


\section{Discussion}

The occurrence of endogenous aberrant variable transcripts, in particular $\mathrm{V}_{\mathrm{k}}$ gene transcripts in murine hybridoma cells presents an obstacle for manipulation of antibodies. Several strategies, including restriction enzyme digestion, for example $B C i \mathrm{VI}$, to eliminate aberrant transcripts have not been fully effective because these transcripts may be expressed at similar or higher levels than the functional ones. To our experience, we initially amplified $1 \mathrm{~F} 11 \mathrm{~V}_{\mathrm{\kappa}}$ PCR products using the mixed primers covering all mouse immunoglobulin families and directly cloned to TA cloning vector without $B C i \mathrm{VI}$ digestion, but all selected transformants contained only undesirable aberrant transcripts. Another attempt was done according to Ding's method by using the same $1 \mathrm{~F} 11 \mathrm{~V}_{\mathrm{K}}$ PCR products, but followed with BCiVI digestion. ${ }^{6}$ The proportion of BCiVI-resistant PCR product (supposed to be functional $V_{k}$ ) was much lower than the digested one (supposed to be aberrant $V_{k}$ ) as demonstrated by agarose gel electrophoresis (Figure 1B, lane 3 from the left). The fainted $1 \mathrm{~F} 11 \mathrm{~V}_{\mathrm{k}}$ band was hardly extracted from gel and cloned into TA cloning vector. Unfortunately, none of transformants was obtained though it had been done several times. This might be due to the insufficient amount of the recovered BCiVI-resistant $\mathrm{V}_{\kappa}$ gene. Based on the hypothesis that amplification of the less proportion of gene encoding functional $V_{\kappa}$ antibodies should be enriched by particular primer pairs among various mouse immunoglobulin $\mathrm{V}_{\mathrm{k}}$ gene families. Here, we therefore demonstrated an alternative strategy to isolate functional transcripts from murine hybridoma clones by selective PCR amplification with eight individual primers, instead of the mixed primers, followed by $B C i \mathrm{VI}$ treatment to differentiate the functional $V_{k}$ gene from the aberrant one. By this strategy, the BCiVI-resistant, functional $V_{k}$ PCR products were much easily obtained and could be directly cloned. Interestingly, those functional $V_{k}$ genes of each mouse hybridoma cell lines were found in all selected transformants, suggesting highly success rate of $\mathrm{V}_{\mathrm{k}}$ gene cloning.

Mouse immunoglobulin (Ig) genes are highly diverse in sequence. ${ }^{13,15}$ In this study we showed that 14 of 17 hybridoma clones, except 2G6, $1 \mathrm{~B} 10$ and $2 \mathrm{H} 2$, contained BciVI-aberrant $V_{k}$ genes when the mixed $V_{k}$ primers were used (as shown by BciVI-digested products in Figure 1B). Some of them obviously demonstrated high proportion of aberrant $V_{k}$ over functional $\mathrm{V}_{\mathrm{k}}$ (clone $1 \mathrm{~F} 11,4 \mathrm{D} 4,2 \mathrm{D} 3$, Figure 1B). It is suggested that the expression of aberrant $\mathrm{V}_{\mathrm{k}}$ is predominant in mouse hybridoma clones. This observation is concordant with other studies describing preferential amplification of aberrant $V_{k} c D N A s$ from mouse hybridoma cells despite using different sets of primers. ${ }^{5,6}$ Nevertheless, we demonstrated that $B c i V I-r e s i s t a n t$ amplicons could be obtained according to our selective primers strategy and functional $\mathrm{V}_{k}$ genes were cloned for all 17 hybridoma clones in this study.

Noted that BciVI-resistant amplicons were obtained using sense primers LVk5, LVk6, LVk19, LVk20 and LVk689 that varied among hybridoma clones; however, BciVI-sensitive amplicons were obtained using primers LVk3 and LVk14
(Figure 2). The latter two primers shared 17/21 nucleotides to each other, and are most similar to the leader sequence of the aberrant $\mathrm{V}_{\mathrm{k}}$ transcript reported previously, explaining why aberrant $\mathrm{V}_{\mathrm{k}}$ gene are frequently amplified by these two primers. ${ }^{3,16}$ Being different from the others, the $B c i$ VI-resistant amplicon obtained from clones $4 \mathrm{G} 2$ and $2 \mathrm{H} 2$ using primer LVk689 was identified as endogenous MOPC21 kappa light chain transcript (GenBank accession no.V00810). ${ }^{17}$ In the early days of hybridoma technology development, mouse myeloma P3-X63-Ag8 derived from MOPC21 tumor cells was used for fusion with mouse B-cells. This immortal myeloma expresses and secretes MOPC21 immunoglobulin, which interferes with hybridoma clone immunoglobulin production. ${ }^{18}$ Therefore, we suspect that these endogenous $V_{k}$ transcripts are produced from the parental mouse myeloma fusion partner (P3-X63-Ag8) which was used to generate 4G2 and $2 \mathrm{H} 2$ hybridoma clones. ${ }^{78}$ The LVk689 primer sequence matches the $\mathrm{V}$ region of MOPC21 Ig kappa light chain, and thus is expected to prime amplification of endogenous MOPC21 transcripts that may be present. In contrast, subclones of P3X63-Ag8, such as Sp2/0-Ag14, and P3-X63-Ag8.653, were later developed to eliminate the secretion of this endogenous immunoglobulin and are still commonly used for generating hybridomas. ${ }^{18}$ No MOPC21 or endogenous immunoglobulin transcript sequences were obtained from the other 15 hybridoma clones, as they were generated from a non-secreting immunoglobulin myeloma fusion partner P3-X63-Ag8.653. ${ }^{9,10}$

For $\mathrm{V}_{\mathrm{H}}$ genes, $500 \mathrm{bp}$ amplicons of functional transcripts were obtained from one or more primer pairs from all hybridoma cells used in this study. The one notable exception is the aberrant $1 \mathrm{~B} 2 \mathrm{~V}_{\mathrm{H}}$ transcript, which contains a premature stop codon at the beginning of CDR3, leading to a non-productive heavy chain variable region. In general, aberrant $V_{H}$ transcripts are rarely reported. $\mathrm{V}_{\mathrm{H}}$ aberrant sequences are more diverse than aberrant $\mathrm{V}_{\mathrm{k}}$. Two aberrant $\mathrm{V}_{\mathrm{H}}$ transcripts (abVH-HF3, GenBank accession no. EU121635; abVH-HF4, GenBank accession no. EU121634) in the myeloma fusion partner P3-X63-Ag8.653 were previously reported by Yazad Irania et. al. ${ }^{14}$ The aberrant $\mathrm{V}_{\mathrm{H}}$ transcripts abVH-HF3 and abVH-LF8 (GenBank accession no. HM046413.1) are 98\% identical and share the same change in the reading frame in the VDJ joining region encoding CDR3 (different from $1 \mathrm{~B} 2 \mathrm{~V}_{\mathrm{H}}$ ), whereas abVH-HF4 harbors a 50 bp deletion in the same region. ${ }^{6,14}$ The diversity of aberrant $\mathrm{V}_{\mathrm{H}}$ transcripts hindered the development of general strategies to select the functional gene for further cloning step.

The putatively productive variable genes cloned from PCR products were verified as functional chAbs with the human IgG1 $\kappa$ backbone. The binding properties of ch2G6, ch1F11 and ch1A4, as well as recognition epitopes are indistinguishable from the original $\mathrm{mAbs}$ by various assays (Figure $\mathbf{4}$ and 5). These results validated our protocol, as summarized in Figure 6 for identifying functional antibody transcripts from mouse hybridoma clones which coexpress aberrant genes. 


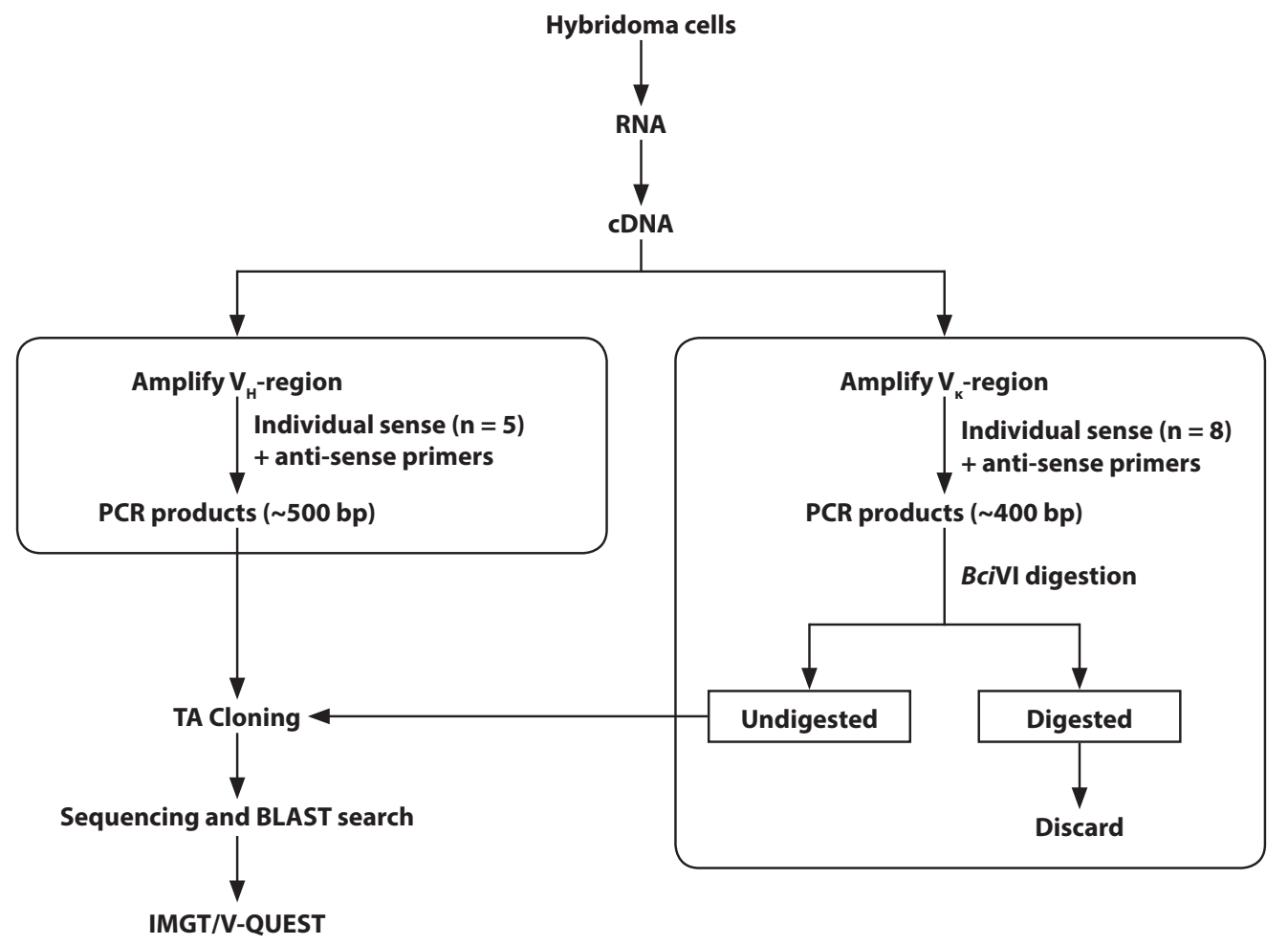

Figure 6. $\mathrm{V}_{\mathrm{H}}$ and $\mathrm{V}_{\mathrm{\kappa}}$ amplification strategy. Murine hybridoma cells were used as sources of immunoglobulin variable domains $\mathrm{V}_{\mathrm{H}}$ and $\mathrm{V}_{\mathrm{\kappa}}$. RNA was extracted and reverse transcribed to generate first strand cDNA. $\mathrm{V}_{\mathrm{H}}$ was amplified with a panel of five sense primers together with a common antisense primer in separate reactions, and the $500 \mathrm{bp}$ PCR products were cloned into the TA plasmid. $\mathrm{V}_{\kappa}$ was amplified with eight individual sense primers and a common antisense primer in separate reactions, and the 400 bp PCR products were digested with BciVI. Digested amplicons were identified as aberrant $V_{\kappa}$ transcripts and only undigested amplicons of putatively productive $\mathrm{V}_{\kappa}$ transcripts were cloned into the TA plasmid. Plasmids containing $\mathrm{V}_{\mathrm{H}}$ or $\mathrm{V}_{\mathrm{\kappa}}$ sequences were analyzed with the IMGT database tool.

In conclusion, we have developed a simple method for cloning variable gene transcripts for both $\mathrm{V}_{\mathrm{H}}$ and $\mathrm{V}_{\mathrm{k}}$ that is reproducible in different mouse hybridoma cells by using 8 individual primer pairs covering most of the mouse immunoglobulin genes. Screening of BciVI-resistant $\mathrm{V}_{\kappa}$ PCR product is a quick and easy way to identify functional $V_{k}$ transcripts and reduce the tedious downstream steps of cloning and selection. This approach is promising for the generation of chAbs as well as genetic archiving of valuable mouse hybridoma clones, which is beneficial for therapeutics and other medical applications.

\section{Acknowledgments}

This work was performed with a financial support of a sub-research project (Project code: P-16-50392.) (to C.P.), belonging under the umbrella of "The NSTDA Research Chair Grant 2015" funded to P.M. by National Science and Technology Development Agency, Thailand. Part of this work was also supported by Newton Fund: MRC-NSTDA grant (to P.M.). We thank Philip J. Shaw for manuscript editing and Andrew Beavil for providing the dual expression plasmid pVITRO1-hTrastuzumab-IgG1к) (Addgene plasmid \# 61883), for chimeric antibody cloning and production.

\section{References}

1. Verweij CL, Vosslamber S. New insight in the mechanism of action of rituximab: the interferon signature towards personalized medicine. Discov Med. 2011;12(64):229-36

2. Rosman Z, Shoenfeld Y, Zandman-Goddard G. Biologic therapy for autoimmune diseases: an update. BMC Medicine. 2013;11:88-

3. Carroll WL, Mendel E, Levy S. Hybridoma fusion cell lines contain an aberrant kappa transcript. Molecular immunology. 1988;25(10):991-5.

4. Ostermeier $\mathrm{C}$, Michel $\mathrm{H}$. Improved cloning of antibody variable regions from hybridomas by an antisense-directed RNase $\mathrm{H}$ digestion of the P3-X63-Ag8.653 derived pseudogene mRNA. Nucleic acids research. 1996;24(10):1979-80.

5. Juste M, Muzard J, Billiald P. Cloning of the antibody kappa light chain $\mathrm{V}$-gene from murine hybridomas by bypassing the aberrant MOPC21 -derived transcript. Analytical biochemistry. 2006;349(1):159-61.

6. Ding G, Chen X, Zhu J, Cao B. Identification of two aberrant transcripts derived from a hybridoma with amplification of functional immunoglobulin variable genes. Cellular \& molecular immunology. 2010; 7(5):349-54.

7. Gentry MK, Henchal EA, McCown JM, Brandt WE, Dalrymple JM. Identification of distinct antigenic determinants on dengue-2 virus using monoclonal antibodies. The American journal of tropical medicine and hygiene. 1982;31(3 Pt 1):548-55.

8. Henchal EA, Gentry MK, McCown JM, Brandt WE. Dengue virus-specific and flavivirus group determinants identified with monoclonal antibodies by indirect immunofluorescence. The American journal of tropical medicine and hygiene. 1982;31(4):830-6.

9. Puttikhunt C, Kasinrerk W, Srisa-ad S, Duangchinda T, Silakate W, Moonsom S, et al. Production of anti-dengue NS1 monoclonal antibodies by DNA immunization. Journal of virological methods. 2003;109(1):55-61. 
10. Puttikhunt C, Prommool T, N Ut, Ong-ajchaowlerd P, Yoosook K, Tawilert C, et al. The development of a novel serotyping-NS1-ELISA to identify serotypes of dengue virus. Journal of clinical virology : the official publication of the Pan American Society for Clinical Virology. 2011; 50(4):314-9.

11. Giudicelli V, Chaume D, Lefranc MP. IMGT/V-QUEST, an integrated software program for immunoglobulin and T cell receptor V-J and V-D-J rearrangement analysis. Nucleic acids research. 2004;32(Web Server issue):W435-40.

12. Dodev TS, Karagiannis P, Gilbert AE, Josephs DH, Bowen H, James LK, et al. A tool kit for rapid cloning and expression of recombinant antibodies. Scientific Reports. 2014;4:5885.

13. Johnston CM, Wood AL, Bolland DJ, Corcoran AE. Complete sequence assembly and characterization of the C57BL/6 mouse Ig heavy chain $\mathrm{V}$ region. Journal of immunology (Baltimore, Md : 1950). 2006;176(7): 4221-34.

14. Irani Y, Tea M, Tilton RG, Coster DJ, Williams KA, Brereton HM. PCR amplification of the functional immunoglobulin heavy chain variable gene from a hybridoma in the presence of two aberrant transcripts. Journal of immunological methods. 2008;336(2):246-50.
15. Collins AM, Wang Y, Roskin KM, Marquis CP, Jackson KJ. The mouse antibody heavy chain repertoire is germline-focused and highly variable between inbred strains. Philosophical transactions of the Royal Society of London Series B, Biological sciences. 2015;370(1676).

16. Strohal R, Kroemer G, Wick G, Kofler R. Complete variable region sequence of a nonfunctionally rearranged kappa light chain transcribed in the nonsecretor P3-X63-Ag8.653 myeloma cell line. Nucleic acids research. 1987;15(6):2771.

17. Hamlyn PH, Gait MJ, Milstein C. Complete sequence of an immunoglobulin mRNA using specific priming and the dideoxynucleotide method of RNA sequencing. Nucleic acids research. 1981;9(18):4485-94.

18. Kearney JF, Radbruch A, Liesegang B, Rajewsky K. A new mouse myeloma cell line that has lost immunoglobulin expression but permits the construction of antibody-secreting hybrid cell lines. Journal of immunology (Baltimore, Md : 1950). 1979;123(4):1548-50.

19. Tiller T, Busse CE, Wardemann $\mathrm{H}$. Cloning and expression of murine Ig genes from single B cells. Journal of immunological methods. 2009;350 (1-2):183-93.

20. Chardes T, Villard S, Ferrieres G, Piechaczyk M, Cerutti M, Devauchelle G, et al. Efficient amplification and direct sequencing of mouse variable regions from any immunoglobulin gene family. FEBS letters. 1999;452(3):386-94. 